\title{
Strategic Self-Disclosure: interpersonal competence of female romantic communication in American media dating culture
}

\author{
ROMANIUK OLEKSANDRA \\ Associate Professor \\ National University "Odessa Maritime Academy" \\ Department of the English Language \\ 8, Didrikhson St., Odessa, 65029, Ukraine \\ E-mail: alexarom2906@gmail.com
}

\section{STRATEGIC SELF-DISCLO- SURE: INTERPERSONAL COM- MUNICATION COMPETENCE OF FEMALE ROMANTIC COMMUNI- CATION IN AMERICAN MEDIA DATING CULTURE}

\begin{abstract}
The paper focuses on strategic Self-Disclosure within female communication in American dating culture. The strategic Self-Disclosure affects mutual dyadic interest and romantic relationship outcomes in media dating behaviour. To increase the chances of the communicative effectiveness the strategic ways are explored, namely what should be said (semantics) and how it should be said (discourse features via verbal means). The strategic ways are implemented by feminine communicative moves sourced from an American dating show "The Bachelor" (2012-2018). They are aimed at achieving the communicative intention - to awaken the male addressee's interest and curiosity by intentionally revealing personal information. The cross-cultural awareness of the strategic SelfDisclosure is mutually beneficial for both native speakers and non-native speakers helping easily to overcome the communication barriers and develop the greater self-confidence of romantic partners.
\end{abstract}

KEY WORDS: Self-Disclosure; interpersonal competence; female romantic communication; American media dating culture; effective communication.

SUMMARY: 1. Introduction. 2 Methodology. $3 . \quad$ Results. 4. Conclusions and discussion.
LA AUTODIVULGACIÓN ESTRATÉGICA: COMPETENCIA INTERPERSONAL DE LA COMUNICACIÓN ROMÁNTICA FEMENINA EN LA CULTURA DE CITAS DE LOS MEDIOS ESTADOUNIDENSES

RESUMEN: El artículo se centra en la autodivulgación estratégica dentro de la comunicación femenina en la cultura de citas estadounidense. La autodivulgación estratégica afecta el interés mutuo y las relaciones románticas en el comportamiento de citas en los medios. Para aumentar las posibilidades de la efectividad comunicativa, se exploran las formas estratégicas, a saber, qué se debe decir (semántica) y cómo se debe decir (características del discurso a través de medios verbales). Las formas estratégicas se implementan mediante movimientos comunicativos femeninos provenientes de un programa de citas estadounidense "The Bachelor" (2012-2018). Su objetivo es lograr la intención comunicativa: despertar el interés del destinatario masculino al revelar intencionalmente información personal. La conciencia intercultura de la auto-divulgación estratégica es mutuamente beneficiosa tanto para los hablantes nativos como para los no nativos, ya que ayuda a superar fácilmente las barreras de comunicación y a desarrollar la mayor confianza en sí mismos de las parejas románticas.

PALABRAS CLAVES: Auto-divulgación; competencia interpersonal; comunicación romántica femenina; Cultura de citas en los medios estadounidenses; comunicación efectiva.

SUMARIO: 1 . Introducción. 2. Metodología. 3. Resultados. 4. Conclusiones y discusión.

\section{LA RÉVÉLATION DE SOI STRA- TÉGIQUE: GUIDE PAS A PAS POUR UNE COMMUNICATION ROMANTIQUE EFFICACE}

RÉSUMÉ: L'article se concentre sur la révélation de soi dans le discours romantique féminin à l'étape Pragmatique de la relation amoureuse. Pour augmenter les chances d'efficacite communicative, les moyens stratégiques sont explorés, à savoir ce qu'il faut dire (sémantique) et comment (les caractéristiques du discours et les moyens verbaux), ainsi que les cause des échecs de la communication féminine. Les moyens stratégiques son mis en œuvre par le noyau central de Mouvements de communication féminins (événement mémorable expérience de rencontre antérieure, louange à soi-même), fournissant une communication romantique interpersonnelle réussie. L'analyse présentée dans cette étude porte sur le corpus romantique féminin présente par 738 mouvements de communication féminins visant à réaliser l'objectif de communication - éveiller l'intérêt du destinataire masculin en révélan intentionnellement des informations personnelles. La prise de conscience interculturelle de la communication romantique stratégique est bénéfique pour les locuteurs natifs, comme pour les locuteurs non natifs, permettant de surmonter facilement les barrières de communication et de développer la confiance en soi des partenaires romantiques en excluant les risques de rupture de la relation amoureuse.

MOTS CLÉS: Révélation de soi; compétence interpersonnelle; communication romantique féminine; Médias américains datant de la culture; communication efficace.

SOMMAIRE: $1 . \quad$ Introduction. 2 Méthodologie 3. Résultats. 4 Conclusions et discussion.
Fecha de Recepción Fecha de Revisión Fecha de Aceptación Fecha de Publicación 


\title{
Strategic Self-Disclosure: interpersonal competence of female romantic communication in American media dating culture
}

\author{
ROMANIUK OLEKSANDRA
}

\section{INTRODUCTION}

Interpersonal communication is a prerequisite for satisfying social needs in particular ways regarding social and cultural standards. This type of communication is defined as the complex, continuous, collaborative process of verbal and nonverbal meaning-making between people who are willing to maximize the presence of their personal (Stewart et al., 2005). Interpersonal communication fulfils certain goals, however, some people are more successful than the others. Therefore, to achieve communicative goals interpersonal communication should be strategic (Jones, 2013). A high degree of interpersonal communication competence helps communicators successfully achieve their goals, so it is necessary "to have an effective repertoire of interpersonal skills" (Hargie, 2011: 2). Interpersonal skills are defined as "a process in which the individual implements a set of goal-directed, inter-related, situationally appropriate social behaviours, which are learned and controlled" (Hargie, 2006: 13).

As a set of effective interpersonal skills, the strategic Self-Disclosure encompasses interdependent variables such as the context (the objective integrative features: place, setting, time, frequency, etc.) and the communicators (subjective integrative features: gender, age, education, previous experience, cultural background). The role of language in interpersonal pragmatics is fundamental (O'Driscoll, 2013). Therefore, a great variety of theoretical approaches to the study of the interpersonal aspect of language can be applied: interactional sociolinguistics (Gumperz, 1982); gender studies (Lakoff, 1975; Tannen, 1996); (critical) discourse analysis (Brown and Yule, 1983; Coulthard, 1985; Stubbs, 1983; Weiss and Wodak, 2003); conversation analysis (Sacks et al., 1974); interpersonal pragmatics (Culpeper and Haugh, 2014; Locher and Graham, 2010), etc.

Over the last two decades, researchers have studied interpersonal communication addressing a broad range of issues such as various aspects of representation and interpretation of meaning in different genres of spoken and written discourse (Dontcheva-Navratilova and Povolná, 2012; Edmondson, 1981; Schiffrin, 2000, etc). Nevertheless, as promising as it may appear, there are still questions that are not being asked. What is much less understood, is how interpersonal communication competence of Self-Disclosure can affect a partner's choice, or what should be said to awaken the addressee's interest? Or indeed, why do some ways provide effective communication, while others cause communication failures? Given this, understanding interpersonal communication competence of the strategic Self-Disclosure is an important undertaking, one with implications for researchers, 
sexual and relationship therapists, dating coaches and other experts in this field.

In this paper, I argue that the investigation of strategic interpersonal communication across different kinds of relationships with their dynamics, cultural and social backgrounds should be based on the complex approach considering variables such as the objective/subjective integrative features and the strategic ways of increasing the communicative effectiveness. The strategic ways are considered as what should be said (semantics) and how it should be said (discourse features via verbal means) within interpersonal dyadic communication. Moreover, the complex approach, combining the communicative-pragmatic sphere "the external context" and the cognitive sphere "the internal context", provided the answers to the questions raised above. However, my intention in proposing a complex approach to interpersonal communication is not to replace the existing ones but to suggest that they can be brought together as a coherent whole, providing the kind of theoretical grounding that is still missing in much of the research on the interpersonal relationship.

According to the social penetration theory provided by Altman and Taylor (1973), the interpersonal dyadic communication changes as the relationships develop. Thus, "social penetration refers to the reciprocal behaviours that occur between individuals [...] and include exchange of information (e.g., attitudes, values, biographical-demographic, and personal data), exchange of expressions of positive and negative effect, and mutual activities (e.g., sports, dating, studying, etc.)" (Taylor, 1968: 79). Moreover, "interpersonal development is thought to proceed along two related dimensions, breadth of penetration or the amount of interaction, information exchange per unit time (for example, the amount of communication per week), and depth of penetration or the degree of intimacy of a typical interaction or exchange" (Taylor, 1968: 79).

Thus, Self-Disclosure is an individual, complicated and intimate process that can be assumed as effective in case dating partners are highly aware of both the strategic ways and the causes of communication failures. Self-Disclosure is an important aspect of interpersonal communication in close relationship including dating and marital relationship (Derlega et al., 1993). It combines both the characteristics of the partner and relationship (Hinde, 1997), and serves as a maintenance strategy (Sprecher and Hendrick, 2004). Also, Self-Disclosure is considered as a powerful mechanism (Finkenauer and Hazam, 2000), and is divided into four categories within the skilled interpersonal interaction: observation, thoughts, feelings and needs (Hargie, 2011).

However, reviewing prior research on Self-Disclosure, it turned out that the romantic type of interpersonal relationship has received less attention: considering that both disclosure and secrecy should have a beneficial effect on satisfaction in close relationship (Finkenauer and Hazam, 2000); explor- 
ing the prediction of relationship satisfaction by means of the communication-related variables, including Self-Disclosure (Meeks et al., 1998); suggesting gender similarity in the pattern of variable relations such as love attitudes, sexual attitudes and Self-Disclosure (Hendrick S. and Hendrick C., 1987); concluding that there are no gender differences in disclosure of accomplishments, however women disclose more feelings than men (Murstein and Adler, 1995); highlighting that Self-Disclosure, implying the disclosure of various types of personal information that can be shared with a partner, involves a feeling of mutual attraction within the romantic dyadic interaction, and, consequently, is determined by the mutual intensification of the Self-Disclosure process, which acquires extensiveness and intensity, affecting the feelings of intimacy among the partners (Greene et al., 2006). Consequently, the early stages of interpersonal communication presented by the superficial disclosure change into the intimate ones as a result of the relationship development (Altman and Taylor, 1973; Derlega et al., 1993). Therefore, the questions outlined above have direct relevance to our understanding of effective Self-Disclosure within female romantic communication.

Self-Disclosure plays a crucial role, since it is aimed at intentionally revealing personal information along with motives, desires, feelings, thoughts, experiences (Altman and Taylor, 1973; Derlega et al., 1993; Fisher, 1994). However, romantic partners, not being fully aware of both advantages and strategic ways regarding Self-Disclosure, prefer to avoid this stage since they believe it makes them vulnerable. Given that, the lack of the ability to reveal personal information is likely to lead to the communication failure of the strategic Self-Disclosure. Thus, mastering interpersonal communication skills is essential as it facilitates competent communication in female romantic communication, arousing the male addressee's interest and curiosity.

The aim of the current paper is twofold. I intend to undertake a clear theoretical assessment of the criteria providing interpersonal communication competence and the practical approach of how the strategic Self-Disclosure may be implemented within female romantic communication increasing the chances of communicative effectiveness. Moreover, according to Dewaele and Salomidou (2017), language and cultural differences within cross-cultural couples made emotional communication more difficult. Thus, the cross-cultural awareness of the strategic Self-Disclosure is mutually beneficial for both native speakers and non-native speakers helping easily to overcome the communication barriers and develop the greater self-confidence of the romantic partners. This excludes the risks of ruining the romantic relationship.

Therefore, I found this interdisciplinary research quite useful for interpersonal pragmatics, discourse analysis, interactional sociolinguistics, gender studies and cross-cultural communication. The multipurpose design along with the complex approach, based on investigating the communica- 
tive-pragmatic and cognitive spheres, are generally applicable to any strategic ways of interpersonal communication aiming at increasing the chances of the communicative effectiveness.

\section{METHODOLOGY}

According to the Popularity of reality TV genres in the U.S. (2016), the statistics and studies from more than 22,500 sources, the interest is growing to such subgenres as cooking, competition, documentaries, supernatural, hidden camera, makeover, travel, and dating show. Yet, there is no unified definition of the reality shows, they share different move structures which are, in turn, realized by different sets of rhetorical strategies (Locher, 2015). The dating show is built on the romantic relationship between the contestants, basically on the feelings of mutual attraction, affection, passion and love. Therefore, the international dissemination arouses the scientific interest in terms of cross-cultural romantic relationship standards along with the criteria revealing the effectiveness of Self-Disclosure.

Dating shows are designed for bachelors and bachelorettes who are willing to find a potential partner. Accordingly, the structure of a dating show is as follows: a bachelor is expected to choose a potential wife among 25 female contestants while they are on romantic dates; the contestants travel to exotic countries; the dates take place in a restaurant, on an island, on a yacht, high in the mountains, etc. This creates an intimate atmosphere, helps the potential partners relax and leads to frank conversations. If the female contestants fail to arouse interest and curiosity, they are eliminated (i.e. 'the losers'). The female contestants who managed to arouse bachelors' interest and curiosity stay for the next stage (i.e. 'the winners'). The aforementioned can be considered as the objective integrative features of the female romantic communication in American media dating culture.

The dating show has already been described in terms of its content and viewer perceptions (Ferris et al., 2007); the media consumption and reception activities of the audience (Hall, 2005; Brophy-Baermann, 2005). However, all these scientific attempts were basically focused on the audience perception of the media characters, and the dating show has not been described in terms of revealing the strategic ways of romantic communication and the causes of communication failures based on the female romantic communication. The subsequent research has proved this framework to be quite robust and Self-Disclosure, presented by the female contestants, analysed for the present study likewise confirms its scientific validity. Moreover, the scientific interest of media characters is based on the same principles that point to the real social connections, providing excellent data for the study of identity construction due to the frequent display of raw emotions (Hoffner and Cantor, 1991; Rubin and McHugh, 1987).

The analytical framework for the current research is the dating show "The Bachelor US". The one is recommended to discuss as discourse since it 
shows a great degree of complexity (Lorenzo-Dus and Blitvich, 2013). The female romantic communication was implemented by a minimum significant functional and structural discourse unit - a Feminine Communicative Move. This is considered as a verbal/non-verbal action of one of the contestants, developing interaction, promoting communication to achieve a communicative goal (Coulthard, 1985; Edmondson, 1981; Schiffrin, 2000; Stubbs, 1983). The most extensive discourse unit as a complex unity of the linguistic form, meaning and action, could be described by the concept of the communicative event (Dijk, 1981: 121-122). For the current study, a Romantic date has been chosen as the communicative event of the female romantic communication. Thus, the romantic discourse is "an interactive communicative-pragmatic and cognitive activity regulated by cooperative strategies and tactics through communicative moves, and characterised by the interdependent variables (objective and subjective integrative features)" (Romaniuk, 2017: 378).

Nowadays, scholars have thoroughly investigated the stages of the romantic relationship development and their features ( $c f$. Crenshaw, 1997; Fisher, 1994; Knapp, 1978; Romaniuk, 2018; Taylor, 1968). According to the present study, the romantic relationships are subdivided into the following stages: (1) Initiation of Romantic Relationship, aimed at getting a relationship started by making the first impression ( $\mathrm{M}_{\mathrm{time}}=30$ seconds); (2) Pragmatics of Romantic Relationship, aimed at providing dyadic romantic pragmatics $\left(\mathrm{M}_{\mathrm{time}}=3\right.$ weeks); (3) Limerence, aimed at the manifestation of a permanent matrimonial relationship ( $\mathrm{M}_{\text {time }}=5$ weeks) (Romaniuk, 2018).

The current paper is a part of a comparative research project devoted to interpersonal communication competence within (1) romantic communication (men vs. women) at different stages of the relationship development based on (2) dating behaviours (media vs. naturally occurring) in (3) dating cultures (American vs. Ukrainian). The focus of the current paper is on the strategic Self-Disclosure within the female romantic communication based on media dating behaviours in American dating culture. Given that, the main research question was put forward:

RQ: What ways of Self-Disclosure can be considered as strategic within the female romantic communication in American media dating culture?

The main research question was then subdivided into three sub-questions:

RQ1: What feminine communicative moves were implemented within SelfDisclosure by the whole group of the female contestants?

RQ2: What are the discourse features and verbal means of the feminine communicative moves?

RQ3: What is the successful pragmatic communication model of the strategic Self-Disclosure? 
The studies of the strategic Self-Disclosure proceeded in five stages:

I. An analytical review of traditional theoretical approaches to the study of the interpersonal aspect of language was undertaken; theoretical sources concerning Self-Disclosure issues; relevance and features of the dating show "The Bachelor US"; the stages of the romantic relationship development. Thus, Self-Disclosure was perceived as an object of the present paper. The general methods of analysis, synthesis, deduction, induction, and generalization were used within this stage;

II. Within the second stage, the descriptive and typological methods, as well as sociolinguistic, conversational and cognitive analyses were used to identify the objective/subjective features of Self-Disclosure;

III. The third stage was dedicated to the collection, processing and transcription of the romantic interactions. The dyadic Self-Disclosure interactions of the female contestants were extracted from the whole video recording. They were transcribed verbatim. The analysis began with chunked coding of the Self-Disclosure interactions. Then, lineby-line coding was performed to develop specific themes (i.e., the feminine communicative moves) within Self-Disclosure as a feminine communicative tactic. Thematic analysis indicated eleven categories of the feminine communicative moves (see Table 1 for further information about the feminine communicative moves, frequencies, and their abbreviations in models and examples).

IV. At the fourth stage, the cognitive-communicative method was used to analyze the communicative-pragmatic and cognitive spheres of SelfDisclosure. At this stage, the intentional, context-situational, pragmatic, lexical, grammatical and stylistic analyses were employed as well as the content analysis method, the quantitative data processing method, and the modelling method. Thus, the analysis of Self-Disclosure at this stage was carried out according to the following algorithm: 1) communicative intention of Self-Disclosure as a feminine communicative tactic; 2) feminine communicative moves and frequency of their usage; 3) semantic groups, discourse features and verbal means of the feminine communicative moves; 4) pragmatic communication models of Self-Disclosure.

V. At the fifth stage, the criteria for the strategic Self-Disclosure and the causes of communication failures were established employing methods of the inductive and deductive analyses, as well as the method of cognitive-discourse interpretation.

The media dating behaviours were presented by the female contestants of the dating show "The Bachelor US". Generally, there are 25-30 female contestants per season. This determined the number $(N=7)$ of the latest seasons released from 2012 to 2018, which, in turn, indicated a required 
sample size $(N=195, M=27.8, S D=1.95)$ : Season $16(N=25)$; Season 17 $(N=26)$; Season $18(N=27)$; Season $19(N=30)$; Season $20(N=28)$; Season $21(N=30)$; Season $22(N=29)$. According to the eligibility requirements, all applicants must be: (1) United States citizens or resident aliens living in the United States, (2) at least twenty-one (21) years of age, and (3) not currently involved in a committed intimate relationship. Thus, the female contestants were US residents from different Regions: The West (35\%); The South (33\%); The Midwest (23\%); The North (9\%). Their age ranged from 21 to 35 (Mage= 26.4 years, $S D=2.65$ ).

Worthy of note, the female contestants were subdivided into two groups: (1) the winners $(N=142)$, i.e., those who impressed the bachelors; (2) the losers $(N=53)$, i.e., those who failed to arouse interest and curiosity. The winners' age ranged from 21 to 33 (Mage $=26.3$ years, $S D=2.5$ ); the losers' age ranged from 23 to 35 (Mage $=26.6$ years, $S D=2.9)$ (Figure 1).

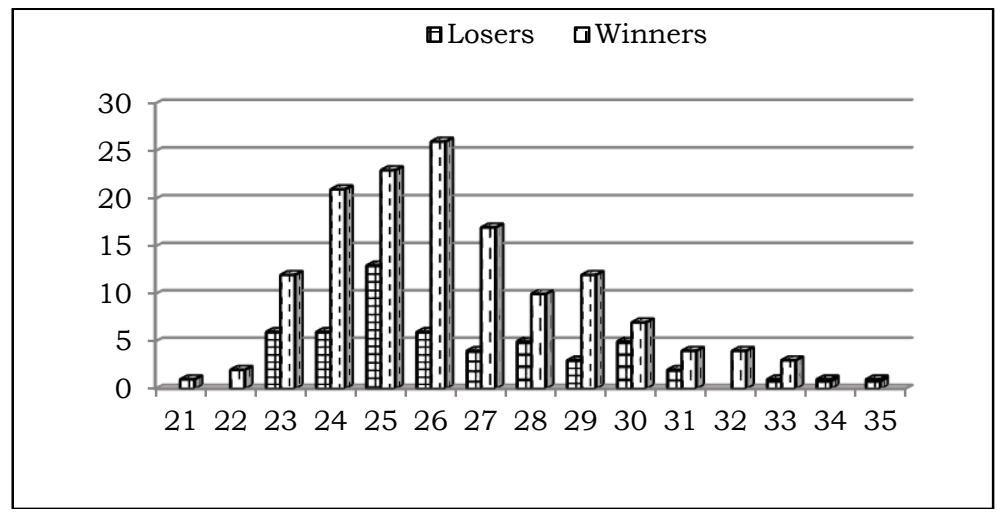

Figure 1: The age of 'the losers' and 'the winners'

The female contestants had a variety of occupations in the field of Economics, Service, Medicine, Education, Fashion, Sports, Media, Art, Law, Agriculture, Politics, Science, etc. The most popular occupations were in the field of Business, Fashion, Medicine, and Service. The gender, place of residence, age, and occupation are perceived as the subjective integrative features.

\section{Results}

Self-Disclosure as a feminine communicative tactic was implemented utilising eleven feminine communicative moves (Table 1). They were aimed at achieving the communicative intention - to awaken the male addressee's interest and curiosity revealing some personal information, exchanging one's feelings and experience. 


\begin{tabular}{|l|c|c|}
\hline $\begin{array}{c}\text { Feminine Communicative } \\
\text { Moves }\end{array}$ & $\begin{array}{c}\text { Abbreviation in } \\
\text { models and exam- } \\
\text { ples }\end{array}$ & $\begin{array}{c}\text { Frequency } \\
\text { n (\%) }\end{array}$ \\
\hline Momentous Event & fME & $182(18.3)$ \\
\hline Previous Dating Experience & fPDE & $159(16.0)$ \\
\hline Self-Praise & fSP & $151(15.2)$ \\
\hline Ideal Partner & fIdP & $126(12.7)$ \\
\hline Personal Future Plans & fPFP & $122(12.3)$ \\
\hline Place of Residence & fRsd & $69(6.9)$ \\
\hline Family & fFm & $52(5.2)$ \\
\hline Ideal Relationship & fIdR & $47(4.7)$ \\
\hline Profession & fProf & $44(4.4)$ \\
\hline Hobby & fHb & $29(2.9)$ \\
\hline Age & fAg & $12(1.2)$ \\
\hline Total & $\mathbf{1 1}$ & $\mathbf{9 9 3}$ \\
\hline
\end{tabular}

Table 1: Feminine communicative moves of Self-Disclosure

The study also provided an analysis of Self-Disclosure as a feminine communicative tactic regarding its semantics, discourse features and verbal means. The discourse features of the feminine communicative moves encompassed: (1) attitude towards the content (i.e. positive, negative, neutral), (2) means of realisation (external, internal, combined); (3) means of expression (explicit, implicit) (Table 2).

\begin{tabular}{|c|c|c|c|c|c|c|c|c|c|c|c|c|}
\hline \multicolumn{2}{|c|}{$\begin{array}{l}\text { Discourse } \\
\text { features, \% }\end{array}$} & $\mathrm{ME}$ & PDE & $\mathrm{SP}$ & IdP & PFP & Rsd & $\mathrm{Fm}$ & IdR & Prof & $\mathrm{Hb}$ & $\mathrm{Ag}$ \\
\hline \multirow{3}{*}{ 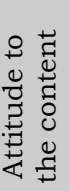 } & Positive & 43.4 & 3.1 & 100 & 100 & 100 & 10.1 & 53.8 & 100 & 20.5 & 100 & - \\
\hline & Neutral & 25.8 & - & - & - & - & 89.9 & 7.7 & - & 79.5 & - & 100 \\
\hline & Negative & 30.8 & 96.9 & - & - & - & - & 46.2 & - & - & - & - \\
\hline \multirow{3}{*}{ 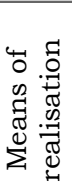 } & External & 26.9 & 17.6 & 29.1 & 46 & 14.8 & 24.6 & 13.5 & 23.4 & 13.6 & 10.3 & 33.3 \\
\hline & Internal & 41.2 & 51.6 & 45.7 & 28.6 & 33.6 & 69.6 & 21.2 & 8.5 & 20.5 & 13.8 & 66.7 \\
\hline & Combined & 31.9 & 30.8 & 25.2 & 25.4 & 51.6 & 5.8 & 65.4 & 68.1 & 65.9 & 75.6 & - \\
\hline \multirow{2}{*}{ 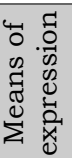 } & Explicit & 100 & 100 & 88.7 & 91.3 & 89.3 & 100 & 94.2 & 83 & 95.5 & 100 & 100 \\
\hline & Implicit & - & - & 11.3 & 8.7 & 10.7 & - & 5.8 & 17 & 4.5 & - & - \\
\hline
\end{tabular}

Table 2: Discourse features of the feminine communicative moves

The semantics of Momentous Event was subdivided into eight semantic groups, expressing:

- the positive attitude towards its content (Example 1): 1) meeting with important people, friends, mentors $(18.1 \%) ; 2$ ) educational achievements at 
school (15.6\%); 3) hobby $(14.2 \%)$; 4) sports achievements in the childhood $(12.9 \%) ; 5)$ pet $(7.9 \%)$;

- the negative attitude towards its content (Examples 2-3): 6) nightlife, parties, drug and alcohol addiction, disco, clubs $(11.8 \%)$; 7) relations with peers $(10.3 \%) ; 8)$ health problems $(9.2 \%)$.

As evident from the figures in Table 2, Momentous Event within female romantic communication was realized explicitly through internal motivation. However, there were cases of combined motivation. For example, the female contestant implemented Momentous Event through internal motivation, which was accompanied by the male partner's situational question 'Oh, how old were you?' aiming at clarifying the provided information. Thus, internal motivation was transformed into combined (Example 1):

(1) " $\mathrm{F}^{1}$ : And you know, when I was little, I went in for sports 'cause my parents always asked me to find time for sport. Anyway, I decided not to choose something that I couldn't imagine my life without. So, I used to twirl ...! (fME)

M: Did you? (mME?)

F: I used to twirl a baton while marching down the streets (fME).

$\mathrm{M}$ : Oh, how old were you? (mME?)

F: I was 10 and I really loved it! (fAg)" [“The Bachelor US”, 2012].

Likewise, the analysis of the female romantic communication revealed the implementation of Momentous Event through external motivation (Table 2). For example, a prerequisite for Self-Disclosure was a series of provocative questions, e.g., 'What's wrong with that?', 'Why not tell me and feel calm?'. They motivated the female contestant to refresh her memory (Example 2):

(2) "M: What's wrong with that? Why not tell me and feel calm? (mME?) F: No, everything is fine. I just don't know where to start... So high school. I... I had an eating disorder (fME).

M: You did? (mME?)

F: Yes. And I think it started 'cause, you know, a lot of things happened in my life. I felt out of control! And the only thing I could control was my weight. So, I decided if I was thinner, I'd be prettier. I'd be happier... and ... it... it was... it was... super body of the year. It was a super party. And my parents just caught me. I was anorexic. When I found out, it was too late. I didn't eat and it was too long... and I... I learned how to be perfect (fME)" [“The Bachelor US", 2012].

\footnotetext{
${ }^{1}$ The abbreviations $F(f)=$ Feminine and $M(m)=$ Masculine are used throughout the examples to identify the addressee's gender
} 
Momentous Event was also realized not only by the situational and provocative questions but also as a result of the requests. For example, the female contestant told the bachelor a dramatic story of her private life as a result of external motivation expressed by the request (Example 3):

(3) "M: So, please, tell me more about you. I wanna know more (mME?)

F: Actually I'm gonna start with... I went to school at University of Arizona and ended up taking a job in Internet advertising. It was like kinda weird period of my life where I had you know money and I was pretty young and there was a lot of partying, travelling. I got to live it up. It was fun. And I didn't really cope and deal with everything in my life. I guess having fun and like partying was my escape. But it was going through and the bachelorette really opened me up again and I kinda rediscovered myself. It was cathartic. And I came back and my business partners, and my best friends, they all noticed this change where I was really open. My sister was so happy in her relationship. And a lot of my friends, I saw them entering that next stage of their life where they had someone they care about and someone they love. And I haven't had that in a really long time (fME)" ["The Bachelor US", 2015].

Apart from the semantics and discourse features, the verbal means of Momentous Event were also characterised: 1) lexical means ${ }^{2}$ of expressing emotions: a) contain positive 'excited', 'inspired', 'happy', 'ecstatic', 'interested' and negative evaluation 'nervous', 'weird', 'freaky', 'embarrassing', 'creepy'; b) combine with adverbial intensifiers 'really', 'so', 'pretty', 'rather', 'kind of'; 2) informal colloquial contractions and discourse markers; 3) different ways of expressing the past: a) usage of verbs in various past tenses; b) constructions 'used to' and 'to be going to'; c) modal verbs 'need', 'should' in combination with 'The Perfect Infinitive'; d) The $2^{\text {nd }}$ and $3^{\text {rd }}$ Conditionals; 4) stylistic devices: 4.1) tropes: hyperbole 'it was... super body of the year'; 4.2) schemes: a) omission, e.g., ellipsis '( I am) Sorry, I don't mean like I am (this type of person); b) repetition: anaphora ' $I$... I had an eating disorder'; anadiplosis 'And you know when I was little, I used to twirl! ... I used to twirl a baton while marching down the streets'; c) structures of balance (a combination of climax with anaphora 'So, I decided if I was thinner, I'd be prettier, I'd be happier').

The following feminine communicative move Previous Dating Experience was subdivided into five semantic groups, expressing:

- the negative attitude towards its content (Examples 4-5): 1) male betrayals (39.1\%); 2) absence of harmonious relationship (30.5\%); 3) one of the partners' unwillingness to marry (21.1\%); 4) ex-boyfriends' alcohol, drugs, and gambling addiction (6.1\%);

\footnotetext{
${ }^{2}$ The emotionally-expressive lexical means presented in the current research were analyzed using AntConc software version 3.4.4w 2014 and listed in descending order of their frequency
} 
- $\quad$ the positive attitude towards its content (Example 6): 5) funny romantic experience (3.2\%).

Also, Self-Disclosure within the feminine communicative move Previous Dating Experience was implemented through internal motivation (Table 2) dealing with the issue of betrayal by an ex-boyfriend (Example 4):

(4) "F: Oh, this gonna be too tough! I had almost the same dating experience. My last relationship lasted for 5 years and he was not going to marry me. I walked away, but I loved him. It was really hard to live without him 'cause I couldn't imagine my life without him. I never felt so lonely (fPDE)" ["The Bachelor US”, 2013].

Previous Dating Experience was also characterised by external motivation (Table 2). For example, the female contestant told about her unsuccessful past experience in dealing with men. Addressee's external motivation expressed by the request made her reveal the intimate details of her ex-boyfriend (Example 5):

(5) "M: I don't know if you wanna talk about it but I'd like to know a little more about your dating history and why you're still available 'cause it's dumbfounded (mPDE?).

F: I met nice people ... I mean really a lot of nice people but I was just not interested in them. I met guys I didn't like or I was not attracted to... Going out all the time, in Hollywood every night... And I dated an actor, you know. Yeah, just never, you know... Good in the beginning, and then it falls apart again. I found underwear in the bed, and you name it. But it's kinda my history. I had some trust issues I am not gonna lie. I've spent so much time with people, the wrong people (fPDE)" ["The Bachelor US”, 2013].

Previous Dating Experience was realized through a combination of internal and external motivation, expressing the positive attitude towards the content (Table 2). For example, the female contestant through combined motivation, expressed by the request, told about her comic experience in the previous romantic relationship. The one helped her understand that the ideal partner should be similar to her brother (Example 6):

(6) «F: C'est la vie. It's a great model. I have also some abysmal dating experience that turning me into your arms (fPDE).

$\mathrm{M}$ : Oh, tell me (mPDE?).

F: Well, I decided that I was just gonna try online dating just to see what it's about. So I signed up all my profile stuff and posted a bunch of overly attractive pictures, you know...you know how it goes... So I had got my 
first e-mail. I was so excited to see like it's my match or whatever and how it worked and at the top was this guy's name Peter, so it turns out to be my elder brother who they have matched me with (fPDE)" ["The Bachelor US", 2012].

Previous Dating Experience was also employed by the following verbal means: 1) lexical means of expressing emotions: a) contain negative evaluation 'jealous', 'offensive', 'wrong', 'shocking', 'tough', and formed morphologically by prefixes ('un-', 'im-', 'in-', etc.) and the suffix '-less': 'unhappy', 'indifferent', 'unwelcome', 'unpleasant', 'hopeless'; verbs 'to fall apart', 'to have some trust issues', 'to break someone's heart', 'to hurt', 'to cry all night long', 'to fade away', 'to completely erase somebody from the memories', 'to leave without goodbye'; also formed lexically by means of the negative particle 'not' along with the action and modal verbs: 'I was just not interested', 'he was not gonna marry me', 'I met guys I didn't like', 'I wasn't attracted to', 'I couldn't imagine my life without him'; b) combine with the adverbial intensifiers 'never', 'hardly', 'rarely', 'barely': 'I've never felt so lonely'; c) use in the form of idioms: 'break someone's heart', 'love is blind', 'the love of my life'; 'all's fair in love and war'; 2) informal colloquial contractions and discourse markers; 3) different ways of expressing the past: a) usage of verbs in various past tenses; b) constructions 'used to' and 'to be going to'; c) modal verbs 'need', 'should' in combination with the 'The Perfect Infinitive'; d) The $3^{\text {rd }}$ Conditional; 4) stylistic devices: schemes: a) repetition (epistrophe 'I've spent so much time with people, the wrong people'); b) omission (ellipsis) '(I was) going out all the time, in the Hollywood every night'; c) changes in the word order (anastrophe) 'just never, you know... good in the beginning'.

The feminine communicative move Self-Praise within Self-Disclosure was expressed by the positive attitude towards one's approval or admiration regarding physical, intellectual, moral, social and other personality traits (Table 2). 'I-image' was expressed by varying degrees of objectivity and subjectivity, i.e. concerning real (59.7\%) or potential (40.3\%) traits and skills. Accordingly, Self-Praise were subdivided into four semantic groups:

1) moral values 52.8\% (Examples 5-7);

2) skills $27.3 \%$

3) intellectual traits $11.6 \%$ (Examples 5,6,8);

4) physical traits $8.3 \%$ (Example 8 ).

Self-Praise was also expressed explicitly (Examples 5-8) and implicitly 'that spectacular and breathtaking view of the city will always come to your mind when you think about me'. Self-Praise was realized through internal motivation (Table 2), for example:

(7) "F: I'm kinda hopeless romantic type like I do believe in real old-fashioned romantic love. I always try to do my best to make my partner feel 
the same way and I just wanna be sincere with you as I am really an honest woman. I hate when people lie or cheat. I am so confident and have a strong personality. I fight for what I want and I go get it (fSP)" ["The Bachelor US", 2013].

The feminine communicative move Self-Praise was implemented through external motivation expressed by the situational questions: 'Anyway, in a relationship are you a giver or a taker?'. Also, the female contestants presented a positive addresser's 'I-image' through the combination of internal and external motivation, expressed by the set of the provocative questions and requests, for example:

(8) "M: When we sat on that boat you said you had kinda accomplished everything. Did you really accomplish (mSP?)?

F: Yeah, I have accomplished everything that I wanted as a single girl. And now I have a lot of experience in getting on well with a partner and memories which can help me to be a perfect wife. Besides, I consider myself to be a dream girl for someone special like you. Sick of being single (fSP).

M: Is that why you have come here, just sick of being single (mSP?)?

F: No, I'm really happy to be here. It's like I'm just someone you need very close all the time. I hope those feelings are mutual. It looks like I am pretty right 'cause you know I am always right (fSP).

M: Still I'd like to know why you're still single so far 'cause you clearly seem to have everything going on, you know (mSP?).

F: Oh, I get what you mean, 'cause like I said I deserve someone special, and I met only ordinary people who were so boring... besides I love walking around wearing pajama pants and no bra so you may see how sexy and hot I am. Seriously, I am the woman who'll inspire you, challenge you and make you smile at the mere thought of me, since I'll do my best to be a part of your life (fSP)" [“The Bachelor US", 2014].

Apart from the semantics and discourse features, the verbal means of Self-Praise were also revealed: 1) lexical means of expressing emotions: a) contain positive evaluation 'romantic', 'honest', 'sexy', 'picky', 'passionate', 'easy-going'; b) combine with adverbial intensifiers 'so', 'pretty', 'really', 'absolutely', 'kinda'; 2) informal colloquial contractions and discourse markers; 3) different ways of expressing the present and future: a) verbs in various present and future tenses; b) modal verb 'can' in combination with 'The Indefinite Infinitive'; c) verbs 'would like', 'plan', 'want', 'mean', 'hope', etc., expressing intentions of the female contestants; d) modal verbs 'may', 'might' and 'could', expressing the uncertainty about the mentioned statement; e) The $1^{\text {st }}$ and $2^{\text {nd }}$ Conditionals; 4) stylistic devices: 4.1) Tropes: a) hyperbole 'I am a dream girl'; b) litotes 'I'm a hopeless romantic type'; 4.2) Schemes: a) omission (ellipsis) '( $\mathrm{I}$ am) Sick of being single'; b) repetition 
(anaphora 'so I like to give, I like to show love and affection'; epistrophe 'It looks like I am pretty right 'cause you know I am always right'); c) structures of balance (climax 'I am the woman who'll inspire you, challenge you and make you smile at the mere thought of me, since I'll do my best to be a part of your life').

The feminine communicative moves Ideal Partner, Personal Future Plans, and Ideal Relationship were similar in terms of their semantics, discourse features and verbal means. They were characterized by the positive attitude towards the content expressed explicitly through internal, external, and combined motivation. They were also limited by the semantic diversity, following the general idea, mentioned in the title of the feminine communicative moves. Ideal Partner, Personal Future Plans, and Ideal Relationship were also employed by the following verbal means: 1) lexical means of expressing emotions: a) contain positive evaluation 'ideal', 'perfect', 'mutual respect', 'cute', 'great'; b) combine with adverbial intensifiers 'really', 'so', 'kinda', 'pretty', 'absolutely'; 2) informal colloquial contractions and discourse markers; 3) different ways of expressing the present and future: a) verbs in various present and future tenses; b) modal verb 'can' in combination with 'The Indefinite Infinitive'; c) verbs, expressing intentions; d) The $1^{\text {st }}$ and $2^{\text {nd }}$ Conditionals; e) modal verbs 'may', 'might' and 'could', expressing the uncertainty about the mentioned statement; f) modal verb 'should', expressing obligation and expectation; 4) stylistic devices: 4.1) Tropes: hyperbole 'I wanna kiss my wife all day long and, you know,... stay in bed'; 4.2) Schemes: repetition (anaphora with amplification 'and I wanna travel around the world with my wife, holding our hands, I wanna wake up and see her lovely eyes smiling at me'; amplification 'that's what I want for my wife, kids, for my own family').

The feminine communicative moves Place of Residence, Family, Profession, Hobby, and Age were also characterised by similar characteristics. These moves were described by the positive and neutral attitude towards the content expressed explicitly through internal, external, and combined motivation. They were also limited by the semantic diversity, following the general idea, mentioned in the title of the feminine communicative moves. Place of Residence, Family, Profession, Hobby, and Age were realised by the following verbal means: 1) lexical means of expressing emotions: a) satisfaction in combination with adverbial intensifiers: 'Indeed, I am really into...', 'I am obsessed with ...', 'I genuinely enjoy working with...', 'I am deeply involved in...'; b) preferences by means of Stative Verbs 'to like', 'to love', 'to enjoy', 'to prefer', 'to adore'; c) idioms 'move up in the world', 'to be a go-getter'; 2) informal colloquial contraction and discourse markers; 3) different ways of expressing the present: a) usage of verbs in various present tenses; b) modal verbs 'can', 'may'; 4) stylistic devices: 4.1) tropes: a) hyperbole 'I am a knowit-all worker'; 4.2) schemes: a) omission (ellipsis '(I am) So into it'); b) repetition (anaphora 'I love kids...I love playing with them').

The feminine communicative moves within Self-Disclosure were presented by the pragmatic communication models which had different effect 
both positive and negative effect on the successful romantic outcomes. This enabled us to compare the feminine communicative moves used within the pragmatic communication models implemented by 'the winners' with those presented by 'the losers'. Accordingly, it was revealed that Momentous Events, Self-Praise, Ideal-Partner, Personal Future Plans, Ideal Relationship, and Profession could affect the partners' choices, while Previous Dating Experience, Place of Residence, Family, Hobby, and Age had no significant effect on the positive romantic outcomes (Figure 2).

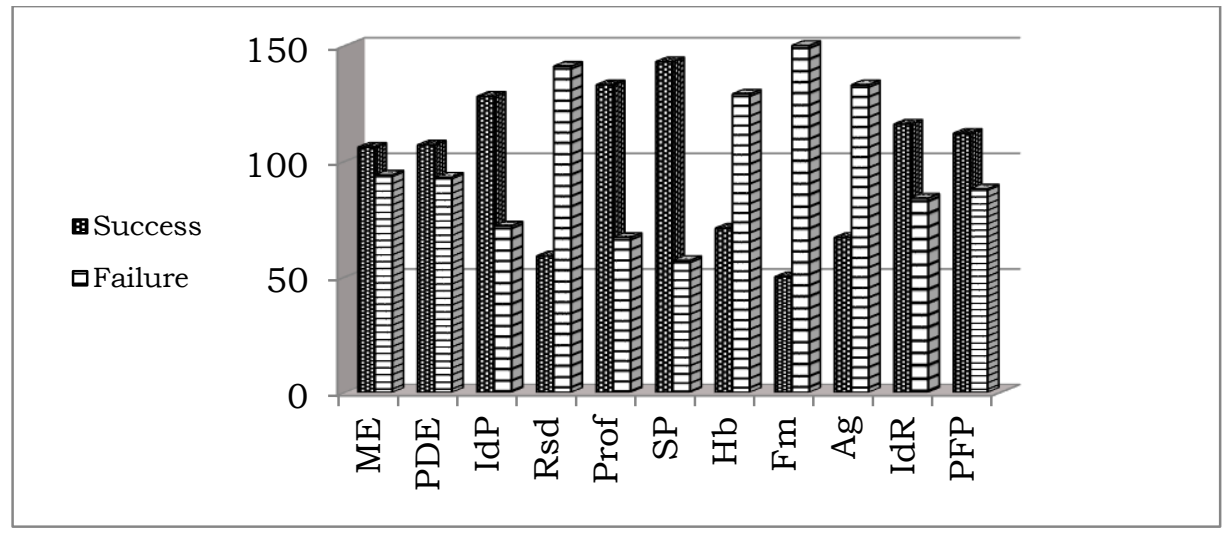

Figure 2: Linear association between the feminine communicative moves

Consistent with this observation, the present results suggest that male partners primarily prefer women who: (1) told them about events and decisions which had a great influence on their future (ME); (2) expressed positive attitude towards one's approval or admiration regarding physical, intellectual, moral, social, and other personality traits (SP); expressed preferences for a dating partner (IdP); (4) outlined personal future plans (PFP); (5) expressed preferences for ideal relationships (IdR); (6) revealed personal information on the profession (Prof). Consequently, the aforementioned feminine communicative moves facilitate romantic relationship development. Conversely, the female contestants also showed the eagerness to reveal personal information on (1) family (Fm), (2) hobby ( $\mathrm{Hb})$, (3) their place of residence (Rsd), (4) age (Ag), and (5) previous dating experience, but these feminine communicative moves within the strategic Self-Disclosure were perceived as irrelevant. The feminine communicative moves were almost identical concerning discourse features and verbal means. They were presented similarly by both 'the losers' and 'the winners'.

Based on the above findings, the causes of the feminine communication failures within Self-Disclosure were identified: (i) deviation from the objective/subjective integrative features; (ii) omission of Momentous Events, SelfPraise, Ideal-Partner, Personal Future Plans, Ideal Relationship, and Profession; (iii) semantic groups' non-compliance with the strategic ones; (iv) ignorance of the successful pragmatic communication model of the strategic Self-Disclosure (Figure 2). 


\section{Conclusions AND discussion}

Interpersonal competence of Self-Disclosure within female romantic communication in American media dating culture was characterised by the effectiveness of achieving the communicative goal and by the appropriateness of the objective/subjective integrative features. The complex approach, combining the communicative-pragmatic sphere and the cognitive sphere, provided new insights into the strategic ways of Self-Disclosure within the female romantic communication.

The findings demonstrated the thematic difference, the linguistic and discourse features, and the frequency range of the feminine communicative moves of Self-Disclosure. The thematic analysis of Self-Disclosure revealed the usage of eleven feminine communicative moves: Momentous Events, Previous Dating Experience, Self-Praise, Ideal-Partner, Personal Future Plans, Place of Residence, Family, Ideal Relationship, Profession, Hobby, and Age. They were aimed at awakening the male partners' interest and curiosity revealing some personal information, exchanging one's feelings and experience, as well as developing and maintaining the successful romantic relationship.

The analysis was undertaken to reveal differing preferences between the winners and the losers of the dating show "The Bachelor US" (2012-2018) within the romantic dates regarding the strategic Self-Disclosure. Consequently, the feminine communicative moves affected the male partners' choice of possible romantic relationship development in both ways (i.e. positively and negatively). Thus, Momentous Events, Self-Praise, Ideal-Partner, Personal Future Plans, Ideal Relationship, and Profession were effective in terms of the strategic Self-Disclosure. By contrast, Previous Dating Experience, Place of Residence, Family, Hobby, and Age had no significant effect on positive romantic outcomes.

Apart from the obvious practical implementations, there is a whole set of theoretical implications fighting for our attention. The interpersonal communication competence of the strategic Self-Disclosure contributes to the growing body of research exploring: (1) interactional sociolinguistics (e.g., the usage of verbal means in their romantic context within the dyadic Self-Disclosure interactions); (2) gender studies (e.g., the strategic Self-Disclosure of female romantic communication); (3) conversation analysis (e.g., the structural organization of Self-Disclosure); (4) discourse analysis (e.g., the feminine romantic discourse and discourse units); (5) interpersonal pragmatics (e.g., the successful pragmatic communication model of Self-Disclosure as well as the causes of communication failures); (6) cross-cultural communication (e.g., the cross-cultural awareness of the interpersonal communication competence of Self-Disclosure; the overall goal of the research project is to maximize the efficiency of interpersonal romantic communication by offering insights into the similarities and differences between dating cultures). 
The findings reported in this study may also point to some implications while teaching Communication and Discourse courses, as well as assisting the textbooks developers to include information on how the effectiveness and the appropriateness of Self-Disclosure affect the interpersonal communication competence.

\section{Acknowledgement}

The author would like to thank the Editors of the academic journal Revista Pragmalingüistica and two anonymous reviewers for their useful comments on earlier drafts of this paper.

\section{REFERENCIAS}

ALTMAN, I. \& TAYLOR, D. (1973): Social penetration: The development of interpersonal relationship. New York, NY: Holt, Rinehart and Winston.

BROPHY-BAERMANN, M. (2005): "True Love on TV: A Gendered Analysis of Reality-Romance Television", Poroi 4(2), pp. 1751. https://doi.org/10.13008/ 2151-2957.1023

BROWN, G. \& YULE, G. (1983): Discourse analysis. Cambridge: Cambridge University Press. http://dx.doi.org/10.1017/CB O9780511805226

COULTHARD, M. (1985): An Introduction to Discourse Analysis. NY; L.: Longman. http://dx.doi.org/10.4324/97 81315835884

CRENSHAW, T. (1997): The Alchemy of Love and Lust: How our sex hormones influence our relationships. New York: Pocket Books.

CULPEPER, J. \& HAUGH, M. (2014): Pragmatics and the English language. Basingstoke, United Kingdom: Palgrave Macmillan. http://dx.doi.org/10.1007/97 8-1-137-39391-3

DERLEGA, V. J., METTS, S., PETRONIO, S., \& MARGULIS, S. T. (1993): Self-Disclosure. Newbury Park, CA: Sage.
DEWAELE, J.-M. \& SALOMIDOU, L. (2017): "Loving a partner in a Foreign Language", Journal of Pragmatics, 108, pp. 116-130.

DIJK, T. (1981): Studies in the Pragmatics of Discourse. The Hague: Mouton Publishers.

DONTCHEVA-NAVRATILOVA, O. \& POVOLNÁ, R. (2012): "Introduction", In Dontcheva-Navratilova, O. \& Povolná, R. (eds.), Discourse Interpretation: Approaches and Applications, Newcastle upon Tyne: Cambridge Scholars Publishing, pp. ix-xiii.

EDMONDSON, W. (1981): Spoken Discourse: A Model for Analysis. London: Longman.

FERRIS, A., SMITH, S., GREENBERG, B. \& SMITH, S. (2007): "The Content of Reality Dating Shows and Viewer Perceptions of Dating", Journal of Communication, 57(3), pp. 490-510.

FINKENAUER, C. \& HAZAM, H. (2000): "Disclosure and secrecy in marriage: Do both contribute to marital satisfaction?", Journal of Social and Personal Relationships, 17, pp. 245-263. https://doi.org/10.1177/ 0265407500172005. 
FISHER, H. (1994): Anatomy of Love. A natural history of mating, marriage, and why we stray. New York, NY: Ballantine Books.

GREENE, K., DERLEGA, V. \&MATHEWS, A. (2006): SelfDisclosure in Personal Relationships. Cambridge: Cambridge University Press.

GUMPERZ, J. (1982): Discourse Strategies. Studies in Interactional Sociolinguistics. Cambridge: Cambridge University Press.

HALL, A. (2005): Yes I Will Accept This Rose: Representation, Consumption, and Identity in $A B C$ 's The Bachelor. Unpublished doctoral dissertation, University of Georgia, Athens, GA.

HARGIE, O. (2006): The handbook of communication skills. London: Routledge.

HARGIE, O. (2011): Skilled Interpersonal Interaction: Research, Theory, and Practice. London: Routledge.

HENDRICK, S. S., \& HENDRICK, C. (1987): "Love and sexual attitudes, Self-Disclosure and sensation seeking", Journal of Social and Personal Relationships, 4(3), pp. 281-297. https://doi.org/10.1177/0265 40758700400303.

HINDE, R. A. (1997): Relationships: A dialectical perspective. East Sussex, UK: Erlbaum.

HOFFNER, C. \& CANTOR, J. (1991): "Perceiving and responding to the mass media characters", in Bryant J. and Zillmann D. (eds), Responding to the screen: Reception and reaction processes, Hillsdale, NJ: Erlbaum, pp. 63-102.

JONES, R. (2013): Communication in the real world: an introduction to communication studies. Irvington, NY: Flat World Knowledge.
KNAPP, M. (1978): Social intercourse: From greeting to goodbye. Needham Heights, MA: Allyn and Bacon.

LAKOFF, R. (1975): Language and woman's place. Harper and Row. http://dx.doi.org/10.1017/S0 047404500000051

LOCHER, M. \& GRAHAM, S. (2010): Interpersonal Pragmatics. Berlin: Mouton.

LOCHER, M. (2015): "Interpersonal pragmatics and its link to (im)politeness research", Journal of Pragmatics, 86, pp. 5-10.

LORENZO-DUS, N. \& GARCÉS-CONEJOS BLITVICH, P. (eds.) (2013): Real Talk: Reality Television and Discourse Analysis in Action. Basingstoke: Palgrave Macmillan. http:/ /dx.doi.org/10.1057/97 81137313461

MEEKS, B. S., SUSAN S., \& HENDRICK, C. (1998): "Communication, love and relationship satisfaction", Journal of Social and Personal Relationships, 15(6), $\quad$ pp. $\quad$ 755-773. http://dx.doi.org/10.1177/02 65407598156003.

MURSTEIN, B. I., \& ADLER, E. R. (1995): "Gender differences in power and Self-Disclosure in dating and married couples", Personal Relationships, 2(3), pp. 199-209. https://doi.org/ $10.1111 / \mathrm{j} .1475-6811.1995$. tb00086.x.

O'DRISCOLL, J. (2013): "The role of language in interpersonal pragmatics", Journal of Pragmatics, 58, pp. 170-181.

POPULARITY OF REALITY TV GENRES IN THE U.S. (2016): In: The Statistics Portal. Online document. 2 May $2017<$ https://www.statista.com/statistics /617828/popularity-reality-tv-genres-usa/>. 
ROMANIUK, A. (2017): "Basic universal units and components of romantic discourse based on the dating show patterns of dyadic interaction", Analele Universității din Craiova, Seria Stiinte Filologice, Lingvistica, 1-2, EUC, Editura Universitaria, pp. 370380.

ROMANIUK, O. (2018): "Feminine contact-establishing communicative tactic within the framework of romantic discourse", Analele Universității din Craiova, Seria Stiinte Filologice, Lingvistica, 1-2, EUC, Editura Universitaria, pp. 170-181.

RUBIN R. B., MCHUGH, M. (1987): "Development of parasocial interaction relationships", Journal of Broadcasting \& Electronic Media, 31, pp. 279-292. http://dx.doi.org/10.1080/08 838158709386664

SACKS, H., SCHEGLOFF, E. \& JEFFERSON, G. (1974): "A simplest systematics for the organization of turn-taking for conversation", Language, 50(4), pp. 696-735.

http://dx.doi.org/10.2307/41 2243

SCHIFFRIN, D. (2000): Approaches to Discourse Text. Oxford: Blackwell Publishers.
SPRECHER, S., \& HENDRICK, S. S. (2004): "Self-Disclosure in Intimate Relationships: Associations with Individual and Relationship Characteristics Over Time", Journal of Social and Clinical Psychology, 23(6), pp. 857-877. https://doi.org/ 10.1521/jscp.23.6.857.54803.

STEWART, J., ZEDIKER, K AND WITTEBORN, S. (2005): Together: communicating interpersonally a social construction approach. New York: Oxford University Press.

STUBBS, M. (1983): Discourse analysis: the sociolinguistic analysis of natural language. Oxford: Blackwell.

TANNEN, D. (1996): Gender and discourse. New York: Oxford University Press.

TAYLOR, D. (1968): "The Development of Interpersonal Relationships: Social Penetration Processes", The Journal of Social Psychology, 75(1), pp. 79-90. http://dx.doi.org/10.1080/00 224545.1968.9712476

WEISS, G. \& WODAK, R. (2003): Critical Discourse Analysis: Theory and Interdisciplinarity in Critical Discourse Analysis. London: Palgrave. 